\title{
The "Bridge" Project: A European Innovative Intergenerational Approach Using Serious Games for People with Dementia
}

\author{
Marina Makri ${ }^{1,2^{*}}$ (), Konstandina Vasiliki Iakovou ${ }^{3,4}$, Minas Dasygenis5, Nikolaos Baras5, \\ Asimina Brouzou", Ioannis Brouzos ${ }^{4}$, Evanggelia Angelidou, ${ }^{6}$ Ioana Caciula7 , Sara Beccati8, \\ Alexandra Manattini' ${ }^{8}$, Magda Tsolaki ${ }^{1,2}$ \\ ${ }^{1}$ Panhellenic Federation of Alzheimer Disease and Related Disorders, Thessaloniki, Macedonia, Greece \\ ${ }^{2} 1^{\text {st }}$ Department of Neurology, School of Medicine, Aristotle University of Thessaloniki, Thessaloniki, Macedonia, Greece \\ ${ }^{3}$ School of Architecture, Aristotle University of Thessaloniki, Macedonia, Greece \\ ${ }^{4}$ Challedu-Inclusion |Games| Education, NGO, Athens, Greece \\ ${ }^{5}$ Department of Electrical and Computer Engineering, University of Western Macedonia, Kozani, Greece \\ ${ }^{6}$ Greek Association of Alzheimer's Disease and Related Disorders of Chalkida, Chalkida, Greece \\ ${ }^{7}$ Asociatia Habilitas-Centru de Resursesi Formare Profesionala, NGO, Bucharest, Romania \\ ${ }^{8}$ Anziani e non solo, NGO, Carpi, Italy \\ Email: *makrimarina@yahoo.gr
}

How to cite this paper: Makri, M., Iakovou, K. V., Dasygenis, M., Baras, N., Brouzou, A., Brouzos, I., Angelidou, E., Caciula, I., Beccati, S., Manattini, A., \& Tsolaki, M. (2021). The "Bridge" Project: A European Innovative Intergenerational Approach Using Serious Games for People with Dementia. Psychology, 12, 1434-1456.

https://doi.org/10.4236/psych.2021.129091

Received: July 6, 2021

Accepted: September 26, 2021

Published: September 29, 2021

Copyright $\odot 2021$ by author(s) and Scientific Research Publishing Inc. This work is licensed under the Creative Commons Attribution International License (CC BY 4.0).

http://creativecommons.org/licenses/by/4.0/ (c) (i) Open Access

\begin{abstract}
Intergenerational activities can be an enjoyable way to act on dementia symptoms, enable people with dementia $(\mathrm{PwD})$ social inclusion and bridge the intergenerational (involving also younger and older people) gap by the direct involvement of young people. The Erasmus+ "Bridge" project has developed eight prototypes Serious Games (SGs) (physical, digital or phygital) and innovative Co-Creation Intergenerational Workshops acting on cognitive and behavioral symptoms of dementia between 2018 to 2021. Partners Greece (Alzheimer Hellas), Italy (Anziani e non solo) and Romania (Asociatia Habilitas) have drafted the methodology of co creation workshops and implemented them following guidelines set. The final eight games have been developed and a second implementation of Game playtesting Workshops was organized in each country in order to assess the impact of the games. In total, $24 \mathrm{PwD}$ co-designed and played some games with the cooperation of 6 game-designers, 16 healthcare professionals, 7 caregivers and 21 young volunteers in the first Co-Creation Workshops. Eleven prototypes games had been created and the team of the project took the final decision to develop fully 8 of them. More specifically, the 8 "Bridge" games developed are the Next destination, Flea market, Find the word, Bird-watching, Emotions, The directors, Blooming flowers, Specialite. These have been tested during a series
\end{abstract}


of workshops in October 2020, organized in partner countries. The testing phase involved 47 people: $23 \mathrm{PwD}, 17$ health professionals, 4 caregivers and 3 young volunteers. Moreover, during the project's lifetime, The Bridge web-platform (https://projectbridge.eu/), contains MOOCs on the methodology of the Game-Creation Workshops and the final 8 selected SGs.

\section{Keywords}

Intergenerational, Workshop, Dementia, Young People, Serious Games

\section{Introduction}

Over the past decades, life expectancy is constantly increasing, resulting not only in a greater number of adults over 65 and 80 years old, but also in an increased number of older adults with age-related impairments on physical or cognitive levels. In 2018, 50 million people worldwide were diagnosed with dementia (Alzheimer's Disease International, 2019). These numbers are expected to increase 281 per cent by 2050 and people living with dementia will be more that 150 millions (ADI, 2020).

There is an absence of intergenerational social activities involving People with dementia $(\mathrm{PwD})$ and many times they are stigmatized and excluded from these activities (D'Cunha et al., 2020). According to World Alzheimer Report (2019) "Around the world, we need to drive forward improvements in healthcare and social care, as well as eliminating the stigma around dementia and ensuring that $P_{W D}$ is included in society.". Moreover, the generation gap is constantly widening as young people are losing their interest to participate in volunteering actions concerning elderly people (Andreoletti \& Howard, 2018). Young people could contribute significantly to fight against the stigma and the consequent loneliness and social exclusion of $\mathrm{PwD}$, especially when engaged as volunteers in projects which challenge them, too (Office for the Ageing, 2016).

Serious games (SGs) are a well known non pharmaceutical practice for cognitive symptoms of dementia with Mild and Moderate Symptoms through stimulating these abilities of PwD (Robert et al., 2014). "SGs", also called "training games" are games designed for a specific purpose other than pure fun (Chi et al., 2017). Moreover, it is proven that traditional boardgames could have a positive cognitive impact when being used with people in mild and moderate stage of dementia (Robert et al., 2014). In addition, in relevant literature review, health professionals and caregivers are searching for non pharmacological interventions to manage also the behavioral and psychological symptoms of dementia (Berg-Weger \& Stewart, 2017). However, there is a lack of relevant approaches using SGs focusing on cognitive and behavioral symptoms of dementia.

The Alzheimer Assotiations and other local services of European countries, as recognising all these trends and facts, have initiated campaigns to raise the 
awareness of general public (Office for the Ageing, 2016). Thus, several European projects have been conducted to develop and include interventions based on the use of games to support larger numbers of $\mathrm{PwD}$ and their caregivers varying from web based games as well as physical games and objects.

One of these initiatives is the "Bridge" Erasmus+ Program. Its main objective is (project code: 2018-1-EL01-KA204-047892) is the creation of games (physical, digital or phygital) focusing on cognitive disfuction and behavioral symptoms of dementia through various integenerationsal workshops engaging younger and older people. "Bridge" project focuses on the creation of tailored content in SGs as a result of the collaborative work among healthcare professionals, members of general public, university students, volunteers, $\mathrm{PwD}$ and game-designers. Thus, an intergenerational empathizing strategy is also created to increase awareness about dementia in members of general public. In this paper, we will address questions related to the design, the development and evaluation of intergenerational co-creation game workshops, the selection and finalization of ideas of SG in order to suit the certain learning needs of our target audiences and the Game Session workshops in which participants tested the eight new SGs. In order to achieve these goals, we will share the results of the implementation and evaluation of the "Bridge" co-creation game workshops and Game Session workshops which took place in three different European countries (Greece, Italy, Romania) and will describe in detail the final eight SGs produced and tested in these workshops as well as the procedure of developing them.

\section{Methodology}

\section{Design and procedure}

The project team is led by Panhellenic Federation of Alzheimer's Disease and Related Disorders (Greece) and is supported by four European partners: Asociatia Habilitas-Centru de Resursesi Formare Profesionala (Romania), Anziani e non solo Società Cooperativa Sociale (Italy), Challedu (Greece), University of Western Macedonia (Greece). The program duration is from September 2018 to August 2021. The research consists of the following steps: (Figure 1).

Prior the implementation of the workshops, a Methodological Guide was created by health professionals in collaboration with game-designers. It focused on how to conduct the co-creation of intergenerational workshops and co-creative game-design workshops, considering special the needs and specifications of games focusing on maximizing benefits of training experience for $\mathrm{PwD}$, Moreover, it includes research on best practice on relevant interventions. The main structure of the methodology of the workshops was based on the results of the previous Greek Bridge Game Jam projects (2017-2018) which were organized by Alzheimer Chalkida and Challedu. Moreover, partners of the "Bridge" project clarified in detail the key points of co-creation workshops based on existing European intergenerational interventions. The materials developed for the workshops (including games, activities, text-based information and presentations) have been adapted to each target group ( $\mathrm{PwD}$, families, young 


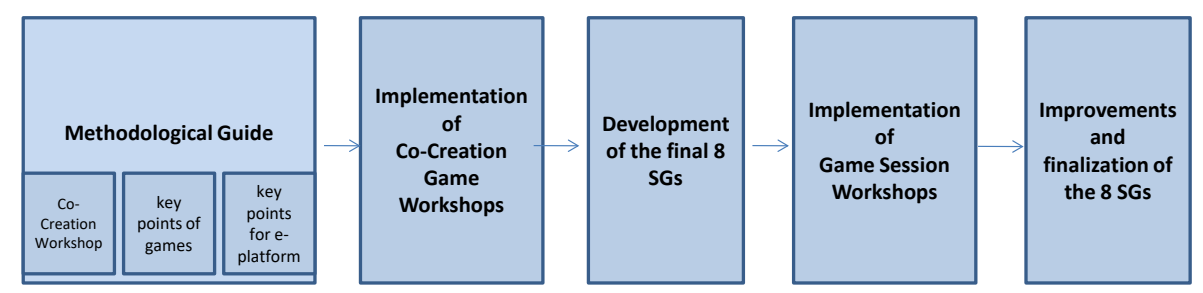

Figure 1. The methodology of the project. Here, we present the main steps.

volunteers and game designers). They also found best practices and tools used to create games within intergenerational workshops and collected recommendations for ensuring the creation of games-ideas that improve behavioral and cognitive symptoms of pwD. Health professionals and game-designers determined the key factors that a SG can address. They analyzed the key points that can improve significantly the effectiveness of a SG on cognitive or behavioral symptoms of PwD.

Step 1: Co-Creation Workshops -Development of working games prototypes Design and Participants

This phase includes the implementation of co-creation workshops in each country and the development of games ideas during them. The main structure of the workshop can be found in Table 1. They took place in three different premises in the day center of Alzheimer Hellas (Greece), in the residential care home of Anziani e non solo (Italy) and in the Emergency University Hospital of Asociatia Habilitas, (Romania).

The project team recruited $\mathrm{PwD}$ and their caregivers from Dementia and Alzheimer associations and other institutions in each country. $\mathrm{PwD}$, who were invited, were in mild stage of the disease, with MMSE (Mini Mental State Examination) scores not less than 22/30. Young volunteers were invited from the Universities that each partner organization is in collaboration being associate partners of the consortium. Game designers were recruited from IT departments and technological educational institutes. Health professionals needed to have a previous experience with $\mathrm{PwD}$ and were invited from health-care organizations and nursing homes. Finally, $24 \mathrm{PwD}$ co-designed and played some games with the cooperation of 6 game-designers, 16 healthcare professionals, 7 caregivers and 21 young volunteers in the first Co-Creation Workshops. Additional participant's characteristics are presented in Table 2 and Table 3.

For $\mathrm{PwD}$ and their caregivers the duration of the workshop was no longer than two hours the 1st day and three hours the 2nd day. The effectiveness of this duration for non pharmacological interventions has been well demonstrated through research findings and also from the experience of implementing non-pharmacological interventions in the Alzheimer Hellas day centers during the last ten years (Chalfont \& Milligan, 2020; Lautenschlager et al., 2014; Tsolaki et al., 2011). This duration provides enough time for PwD to play SGs and provide feedback on their experience. Any shorter and people may feel rushed, and any longer and people may begin to disengage. For the other participants the duration was five hours in the 1st day and three hours in the 2nd day. 
Table 1. The structure of the Bridge Co-creation workshop.

\section{DAY 1}

1. Introducing the workshop's objectives to young people (60' minutes-presentation)

- Overview of the Bridge project

- Background on Dementia

- How to interact with PwD

- Benefits of Serious Games

- Developing Serious Games targeting to PwD

- Instructions for the workshop

2. Handing the information sheets, signing the informed consent by the participant, collecting the demographic data (15' minutes)

3. Creation of mixed 2 - 3 groups. Each group consist of $1-2$ PwD, 1 health professional, 1 - 2 carer, 3 young volunteer, 1 game designer) (30' minutes)

4. Interactions within these groups. Discussion about the preferable games of each participant. A questionnaire was used by the game designer, the groups were asked about their needs, games used in the past and present (30' minutes)

5. Start playing (60' minutes): Pazzel, taboo, jenga, animals-plants, cartoons

6. Break PwD are leaving (15' minutes)

7. Registration and evaluation of the game ideas ( $30^{\prime}$ minutes)

8. Start creating new games ( $60^{\prime}$ minutes)

\section{DAY 2}

1. Explaining the rules of each game (15' minutes)

2. Play the new games in groups, Observation ( $60^{\prime}$ minutes)

3. Break and Improvements of the games (30' minutes)

4. Presentation of the game from each team (30' minutes)

5. Give feedback (20' minutes)

6. Answer a questionnaire (20' minutes)

7. Conclusions and Farewell

Table 2. Participant's in numbers in the 3 Co-creation workshops.

\begin{tabular}{ccccccc}
\hline People Country & PwD & Caregivers & Young people & Health professionals Game designers Total \\
\hline Greece & 13 & 3 & 14 & 3 & 3 & 36 \\
Romania & 6 & 3 & 5 & 5 & 1 & 20 \\
Italy & 5 & 1 & 2 & 8 & 2 & 18 \\
Total & 24 & 7 & 21 & 16 & 6 & 74 \\
\hline
\end{tabular}

Table 3. Participant's characteristics in the 3 Co-creation workshops.

\begin{tabular}{ccccc}
\hline $\begin{array}{c}\text { Characteristics } \\
\text { People }\end{array}$ & $\begin{array}{c}\text { Age } \\
\text { (mean/range) }\end{array}$ & Gender (M/F) & $\begin{array}{c}\text { Educational } \\
\text { level (years) }\end{array}$ & $\begin{array}{c}\text { Previous experience } \\
\text { with games (yes/no) }\end{array}$ \\
\hline PwD & $71 / 43-89$ & $8 / 16$ & $11 / 2-20$ & $6 / 18$ \\
Young people & $24 / 19-32$ & $4 / 17$ & $15 / 12-17$ & $9 / 12$ \\
Caregivers & $54 / 40-64$ & $2 / 5$ & $13 / 10-18$ & $2 / 5$ \\
Health professionals & $41 / 25-68$ & $2 / 14$ & $17 / 12-22$ & $8 / 8$ \\
Game designers & $39 / 26-50$ & $5 / 1$ & $18 / 16-22$ & $5 / 1$ \\
Total & $46 / 19-89$ & $21 / 53$ & $15 / 2-22$ & $30 / 44$ \\
\hline
\end{tabular}




\section{Data collection}

Throughout the workshops, data was elicited through multiple qualitative methods, including:

- Reflexive field-notes and on site observations from game designers and health professional.

- Focus group discussions with $\mathrm{PwD}$, their caregivers and young people.

- Qualitative questionnaire giving feedback for the workshop and the games from all the participants immediately after the workshop was concluded, using open and closed-ended questions.

The mixed qualitative method was divided into four specific categories, according to the structure of the workshop. More specifically:

1) Questions asked by the Team Leaders, Interaction in the group,

2) Feedback from playing the new game prototypes (ideas) in groups observation,

3) Evaluation of the workshop by $\mathrm{PwD}$ and their caregivers and,

4) Evaluation of the workshop by Health Professionals, Game Designers and Young people.

\section{Procedure of the workshop}

The workshops started with a presentation addressed to all the participants, except from $\mathrm{PwD}$. Using a specific structure presentation (ppt), health professionals introduced the content and the aim of the workshops and provided a background on the development of this idea. A template with basic information about dementia, SGs and benefits, on how to interact with PwD and to develop games targeting $\mathrm{PwD}$ was provided to participants. Since young volunteers giht not have experience dealing with $\mathrm{PwD}$ prior to the workshop, it was important that health care professionals guided young volunteers on how to approach $\mathrm{PwD}$ and how to handle specific situations or react to specific incidents.

After the presentation, PwD were invited to participate in the workshop. An information sheet was shared, and demographic data was collected. Participants were informed that all the personal data will be confidential, in accordance to GDPR regulations. Mixed groups started actively interacting while discussing the games they used to play in the past and the games they were currently playing. Through this interaction, game designers extracted the needs of $\mathrm{PwD}$ and preferences. This qualitative data collection was based on a specific questionnaire drafted by all project partners. Some examples of the questions are: Which kind of games did you play when you were a child? Which kind of games do you use to play now? Which kind of games do you usually play with your son or grandson? Do you prefer ICT games or traditional board games? Do you prefer to play games alone or in group?

Once the questionnaire was filled in, the groups were involved in playing different types of existing SGs which were proposed in the Methodological Guide like Puzzles (2d-3d), taboo, jenga, animals-plants, cartoons. Game rules were slightly changed so as to engage people with dementia and decrease the level of 
difficulty.

After this session, game designers, health professionals and young volunteers were involved in creating new game ideas and draft prototypes based on the information gathered from the interaction with PwD.

During, the $2^{\text {nd }}$ day, the game designers introduced the new game ideas and draft prototypes to participants and explained the rules of each game. Mixed groups were created and all participants played the new draft prototypes of games (both for physical and digital games). The interaction between $\mathrm{PwD}$ and other participants was closely observed and all meaningful observations as well as all creative ideas were carefully collected and documented. Some questions of the observation guide were: Did people appear to enjoy engaging with the game? Did people improve on the game as they continued to play? Did people find anything particularly difficult when playing the game?

Once the new games were tested and additional feedback, through a discussion, on ways to improve the games was provided. Adding to this, $\mathrm{PwD}$ gave feedback on their personal experience during the workshop. For instance, they answered: What did you like about the game? Were there any particular features (music, graphics, colours) of the game that you liked? Do you feel the game offered you any benefits? Did you experience any difficulties when playing the game?

After a short break, PwD and their caregivers were asked to fill in a questionnaire reporting the level of satisfaction and support during the workshop. Relevant questions are: Do you feel the workshop offered you any benefits? Was the cooperation with young people satisfied? Do you think that it is important to organise similar workshops? Do you consider that the "Game creation" used in this session facilitate cognitive training or social skills development?

Once the PwD activities completed, the professionals, young volunteers and game designers discussed about the ideas and draft prototypes games in detail and some improvements were followed. Questionnaires for professionals, volunteers and game designers were then completed and collected concerning the experience participating in such workshops and the new games. For instance, some of the following questions were asked: Did you find the workshop interesting? What did you like more? What did people seem to enjoy about the workshop? What information do you think is needed to encourage PwD and their caregivers to use SGs or activities?

\section{Step 2: Development of the eight ideas to prototypes of serious games}

The implementation of the workshops produced eleven ideas and draft prototypes of the games, which were adapted by the project team to the final eight SGs. To obtain these results, they have taken into account all the remarks of the participants of the workshops and the project partners who were responsible for game design (Challedu and UOWM) begun to develop the 8 ideas and draft prototypes to SGs.

Game designers of Challedu reviewed all the comments of participants in 
workshops and developed eight Game-design Documents. The Game design documents clarified the main purpose of each SG, the type of the game (physical, digital, phygital), the number of players and interaction between them and with the game, the main steps of game play, the game elements to be used and the different levels of the game that reflect the difficulty level according to the skills of PwD. Furthermore, it included specifications on graphic design, text and sound (typefaces to be used, color contrast, combinations of words and texts, requirements on User Interface design in digital and phygital games) and proper User Experience Design (facilitating PwD to engage with the rules of board game, facilitating PwD to play a game using tablet with small effort). The game designers of Challedu gave specific attention to create SGs according the criteria:

1) To enhance the cognitive and behavioral skills of PwD.

2) To provide the sense of inclusion, involvement, empowerment and success.

3) To provide to professional caregivers the opportunity to specify the level of difficulty in the game to reflect better the skills of PwD.

4) To be cooperative (for board games especially) to promote inclusion and sense of belonging rather than competition and exclusion.

5) To have interesting topics for PwD.

6) To be easy to train or to support players during playing.

Regarding the digital games, Challedu developed their graphics and cooperated with UOWM in developing the games. UOWM followed the game-design documents and programed the games. When the first beta version of each game was released Challedu proposed improvements based on the game-design documents and their experience during the development of physical and phygital games.

Step 3: Game Session Workshops Testing the eight prototypes serious games

\section{Design and Participants}

After having finalized beta versions of the 8 games, the project team arranged play-testing workshops with the target groups facilitated by health professionals in order to provide feedback on refining the SGs results regarding cognitive and behavioral symptoms. During the implementation of the Game-sessions workshops, university students and volunteers together with $\mathrm{PwD}$ and caregivers tested all the SGs and gave feedback. The main structure of the workshop can be found in Table 4. The recruitment process followed the same steps and criteria as the previous workshops. These workshops were organized by the day center of Alzheimer Hellas (Greece), the residential care home of Anziani e non solo (Italy) and in several residential facilities for older people and day centers for pwD, (Romania). In total, twenty three (23) PwD played and tested the eight SGs in collaboration seventeen (17) healthcare professionals, four (4) caregivers and three (3) young volunteers. The number of participants in the game-session workshops is presented in Table 5 and the number of people who test each game in the game-session workshops can be found in Table 6.

Data collection 
In each workshop the project team used Feedback Questionnaire for the workshop (structure, feelings, opinions), examining the level of satisfaction, support during the workshop, etc. Also, organizers circulated Feedback Questionnaire for the 2 games that were tested in each workshop focusing on specific questions about the design, the interface, the satisfaction etc. in order to assess the games and to release the finalized version.

Table 4. The structure of the Game Session Workshop.

\section{DAY 1}

1. Prior to the beginning of the workshop (10' minutes)

- HCP should provide an information sheet

- Gather demographic data of the participants

2. Creation of mixed groups (10' minutes)

- HCP will create the right 2 mixed group

- HCP give advice to the participants for the procedure of the workshop (especially to young volunteers)

3. Explaining the rules of Game 1 (10' minutes)

4. Play the Game 1 (30' minutes)

5. Explaining the rules of Game 2 (10' minutes)

6. Play the Game 2 (30' minutes)

7. Answer a questionnaire (20' minutes)

- About experience of the workshop

- Evaluate the games

Table 5. Participant's in numbers in the Game-session workshops.

\begin{tabular}{cccccc}
\hline People Country & PwD & Caregivers & Young people & Health professionals & Total \\
\hline Greece & 4 & 1 & 3 & 1 & 9 \\
Romania & 13 & 0 & 0 & 7 & 20 \\
Italy & 6 & 3 & 0 & 9 & 18 \\
Total & 23 & 4 & 3 & 17 & 47 \\
\hline
\end{tabular}

Table 6. Numbers of people who test the games in the Game Session workshops.

\begin{tabular}{cccccc}
\hline Games & PwD & Caregivers & Young people & Health professionals & Total \\
\hline Blooming Flowers & 8 & 1 & 3 & 11 & 23 \\
Specialites & 10 & 2 & 3 & 11 & 26 \\
Emotions & 10 & 2 & 3 & 12 & 27 \\
The Directors & 7 & 2 & 3 & 11 & 23 \\
Next Destination & 17 & 3 & 3 & 8 & 31 \\
Flea market & 17 & 2 & 3 & 9 & 31 \\
Find the word & 18 & 3 & 3 & 8 & 32 \\
Birdwatching & 19 & 3 & 3 & 9 & 34 \\
\hline
\end{tabular}




\section{Procedure of the workshop}

The project team created a Template of Game Session Workshops in which there is detailed information on how to create and implement this kind of workshop (Table 4).

Prior to the beginning of the workshop, the professionals provided the participants with information sheet and gather demographic data. After collection of this data, mixed groups (each group consist of: 1 - 2 PwD, 1 - 2 carers, 1 - 2 young people, 1 health professional) were created and the health professionals gave advice to the participants for the procedure of the workshop. It is important that health professionals give advices to young volunteers on the abilities of $\mathrm{PwD}$, their needs and the activities that help to improve their cognitive skills and reduce their behavioral symptoms. Explanations about the rules of Game 1 were followed and the groups played the Game 1. The same procedure was followed for the Game 2. The Questionnaires to get workshop's feedback and to collect feedback about each game were provided by the health professionals. Attendants answered the Questionnaires about their experiences in the workshop, the benefits and the limitations of this procedure and some specific characteristics of each game.

Step 4. Improvements and finalization of the 8 games

According to the suggested approach, the evaluation and feedback stage is an essential part of the design process of the games. It conducts learning targets during production to discover what isn't working and assist in creating a SG that is truly beneficial. In addition, it can be conducted summarily, after development, to prove that the SG is a genuinely beneficial assessment. The project game designers have used the key elements of SGs development in order to create a safe environment for the evaluation of the games. The evaluation's goal is to uncover the game's effectiveness, adaptability, and usefulness.

After UoWM and Challedu received the feedback from the Game Session workshops, they made the appropriate changes to finalize the games designed. Emphasis was placed on the pedagogical and learning aspect of the games.

\section{Results}

\subsection{Development of Games}

In this section, the evaluation of the different steps of the development of games (from co ceration workshops, to testing and evaluating prototypes) will be presented based on evaluation questionnaires distributed in each stage and partners' assessments.

More specifically, in co creation workshops workshops, people belonging to different age groups had the chance to exchange knowledge and experiences. Before the actual workshop presentations with information about the workshop objectives, the information about dementia, SGs and PwD tool place with all the participants evaluating them as very useful. The benefits of the workshop to older people were numerous, since for most of them the opportunity to engage in 
entertaining and interesting activities and to discuss their experiences was motivating. During the workshops, PwD confirmed that being involved in social activities were among the first benefits they could think of in relation with the activities done during this workshop. The part of the workshops in which $\mathrm{PwD}$ were directly involved in playing games was enjoyable for all participants and none of them showed any signs of fatigue. According to the multiple qualitative methods that data was elicited, the results can be summarized in the following sections:

1) Questions asked by the Team Leaders in cocreation workshops-Interaction in the group

The interviews aimed dive into the past and let participants recall memories of their childhood and youth. Some of them realized to have common memories like the games they used to play when they were children. The games that PwD used to play in childhood were both indoors games and outdoors which require physical movements. Some examples: Card games, Dice games, Hangman, Catch the ball, Jumping rope, Bricks, Hopscotch, Bingo, Blind Fly, Rope, Spinning Top. The games that $\mathrm{PwD}$ are now enjoying are mainly traditional table games, but also some digital games that involve manual work or cognitive skills. The games mentioned by the participants are as follows: Remy, Chess, Backgammon, Bingo, Ball games, Cards, Crossword, etc. The games they usually played with their sons/grandsons were Legos, Puzzles, Memory Cards, Match pairs, Backgammon, Chess, Card games, Domino, etc.

All participants agreed that they would like to have someone to explain the rules and to help them with the game. Some of them underlined that they need more help playing board games. Also, participants agreed that they need games with larger particles (pawns pieces) and legible words and images (using larger font size as well as bigger images). They also liked better to play games using images that are easier to recognize. They prefer to play games alone, but also in the groups. PwD want to engage in games involving two or more people, being eager to socialize. They underline that their preference depends on the kind of game.

2) Findings from observation of new game ideas

All team leaders agreed that the participants seemed to be enjoying all new games. They seemed to enjoy the cognitive training, the teamwork, the social interaction, the design and the challenges of the games. The games had the following benefits: stimulated memory abilities, attention, self-monitoring and performance of goal-directed behavior. They also enhanced cooperation and involvement in activities that were related to real life. In all games, participants improved their game technique/strategy as they played, because they got familiar with the rules, the procedure and the interaction with other players.

Participants encountered, though, some difficulties while testing the new games. For example, they had a difficulty to understand the rules and the guidance and there was a need to repeat rules again during the game. They proposed 
that the colors of shapes must be in contrast and that images related to elderly would improve the game. Also, large objects or large images given the possible fine motor and sight difficulty. Maybe it will be better if each team consists of less people and they proposed also to include a system to write down who is the winner of its round. Some of them added that it will be better if we set time limit. These difficulties and proposed changes were taken into account for the improvement of the games.

\section{3) Evaluation of the cocreation workshop by $P_{w D}$ and their caregivers}

According to the results of the questionnaire which was completed at the end of the workshops and the general feedback, the level of satisfaction of PwD was increased. 80 per cent of the participants answered that the cooperation with young people was pleasant. 76 per cent of $\mathrm{PwD}$ and their caregivers felt that the workshop offered them benefits, and for most of them the opportunity to engage in some fun and social activities and to discuss their experiences was motivating. Also, caregivers mentioned that they discovered the existence of SGs as innovative tools acting on cognitive and behavioral symptoms of dementia. 70 per cent of the participants felt that the workshop was organized in a supporting environment and 89 per cent strongly agree that they wish to take part in similar workshops. The results are summarized in Figure 2.

4) Evaluation of the cocreation workshop by Health Professionals/ Game Designers/ Young people

Do you feel the workshop offered you any benefit?

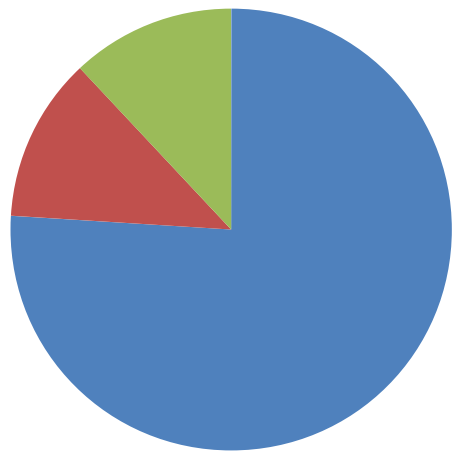

Do you think that the people supporting you today?

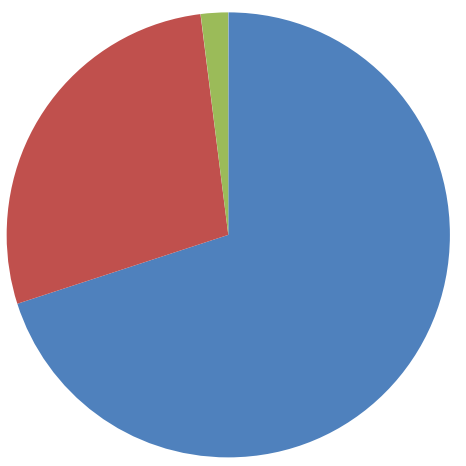

Was the cooperation with young people satisfied /pleasant?
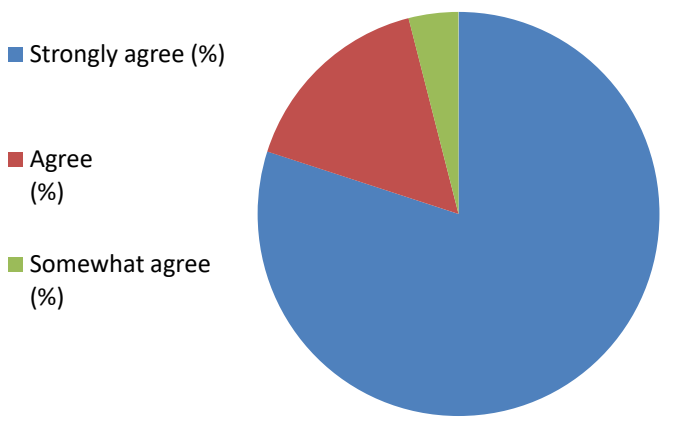

Strongly agree (\%)

Agree (\%)

Somewhat agree(\%)
Do you think that it is important to organise similar workshops?

Strongly agree (\%)

Agree (\%)

- Somewhat agree (\%)

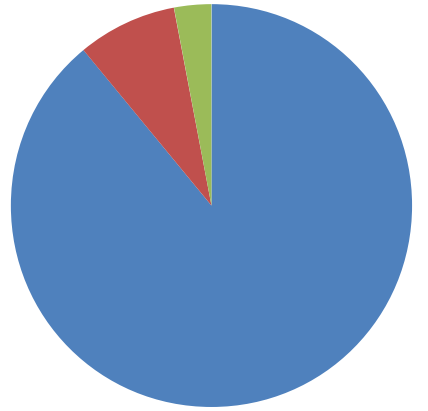

- Strongly agree (\%)

Agree (\%)

Somewhat agree $(\%)$

Figure 2. Feedback from $\mathrm{PwD}$ and their caregivers for the Co-creation workshops and games. 
The project through the workshops supported young people to obtain transferable skills in communication, creativity, critical thinking and social competences. The training presentation which was included in the first part of the workshop improved knowledge and competences about older people and dementia. Many young participants stated that through this interaction, they feel more compassionate towards dementia and 3rd age people. Essentially they are able to better attend to the needs of PwD in care. It was very interesting to have this holistic approach and to look at the field of dementia considering perspectives of different groups. Also, these workshops create awareness and motivation about the importance and possibilities of SGs as tool for improving the quality of life of PwD.

In more details when asked whether the cocreation workshop was interesting and what did they liked more, most people were satisfied that the team consisted of different kind of people since it was a great chance for each group to express their opinions and their perspectives. They liked the creative procedure on developing new games, the interaction in the workshop was not competitive and they had the chance to test the games that they thought and created.

When asked whether people appear to enjoy engaging with the co-creation of the games and what did people seem to enjoy about the workshop, all participants agreed that $\mathrm{PwD}$ tried a lot for the best results, had a good cooperation with the rest of the team and they followed a specific strategy in order to improve their performance. There were also a lot of benefits from the expression of their opinions, social interaction, and cooperation with people of different ages, being a team member who was responsible to remember a part of the creation, cultivation of the cognitive abilities and creation of games that can be playing also at home.

They also underlined that PwD participating in the groups didn't find anything particularly difficult in the workshop and they wished to take part again in similar workshops. Some of them emphasized that there was a problem in the beginning for understanding the rules and the guidance and some difficulties to find the words and the limitation of the time.

5) Findings during the development of the 8 prototypes of games

After the implementation of the co creation workshops eleven ideas and draft prototypes of games have been developed. The final results of the Workshop in Greece were three new games with the contribution of all groups. The games that were created were as follows: "Find the correct rank", "Find the word" and "What's on my mind?". In addition, during the workshop in Italy, three concept ideas have been developed, two physical games and one digital game: "Look, take and put", "My trip" and "Tradition in the kitchen". Finally, in Romania, 5 game ideas were created: "Fruits and vegetables", "Mountain trip", "Associating senses with objects", "Associating emotions with sounds" and "Word association in recognizing common proverbs".

During the $2^{\text {nd }}$ project Transnational Meeting in Bucharest partners discussed 
on the criteria of selection of game ideas that will be developed further and reviewed all the details of the eleven games in order to conclude in the eight final game ideas to be developed during "Bridge" project. Partners considered it valuable to select ideas that can result in enhancing cognitive and behavioral symptoms and that can apply in more than one country.

They finally concluded in developing the following four digital, three physical (table-top) and one phygital game, the description of which follow:

a) "Blooming flowers" is a co-operative board game for all the family including PwD. In this game the players have to collaborate in order to create beautiful bouquets of flowers. The target of the players is to create during the game five bouquets from four to eight flowers (Figure 3 ). The game aims to enhance social skills, memory, observation, concentration and other cognitive and behavioural skills.

b) "Specialites" is a co-operative board game aiming to enhance cognitive, social and behavioural skills of PwD. During the game, the players work closely together to create a recipe. One of the players is selected to be Chef and knows the recipe he/she wants to create. The others try to guess the recipe by looking the appropriate ingredients (Figure 4 and Figure 5). The main goal of the players is to create together three recipes (one breakfast, one main dish and one dessert).

c) "Emotions" is a storytelling phygital game that aims to stimulate emotional recognition and reminiscence in $\mathrm{PwD}$. It is a cooperative game in which all the players try to guess the emotions of a sound, recall and tell a story about it (Figure 5).

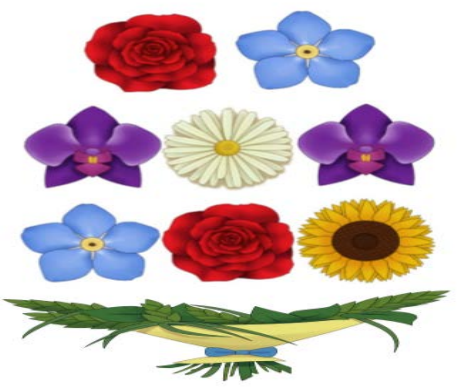

Figure 3. The physical game "Blooming flowers".

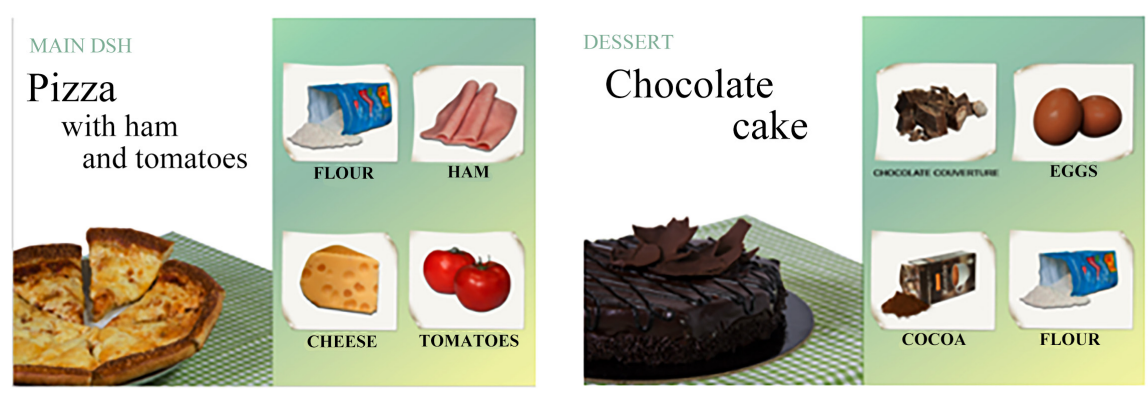

Figure 4. The physical game "Specialites". 

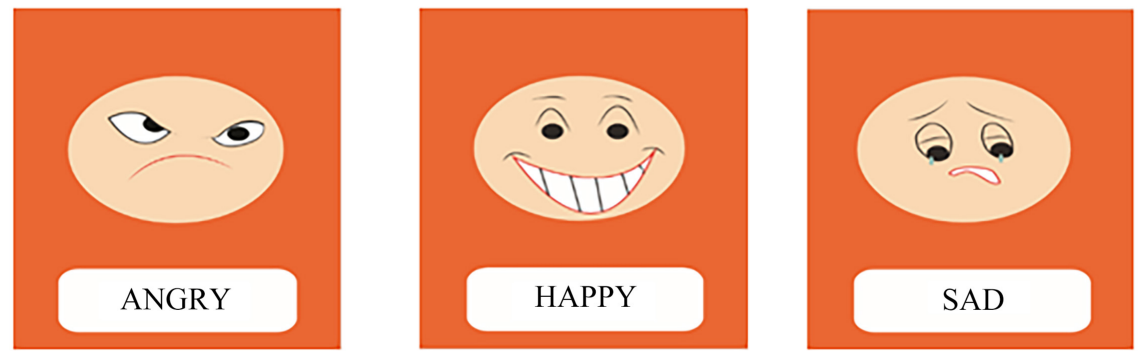

Figure 5. The phygital game "Emotions".

d) "The Directors" is a cooperative board game in which all the players should try to create a theatrical play based on the scenario of the game. Players have to select the proper actors, movements, objects for scenery and songs. The game aims to stimulate cognitive and social skills as well as the motor ones (Figure 6).

e) "Find it" is a digital game (both for PC or tablet) in which players are asked to recognize the negatives of images or to select the part of the image that has been cut (Figure 7). It stimulates observation, critical thinking, creativity and attention.

f) "Next destination" is a digital game for tablet where the player has to prepare her/his luggage for different destinations. The main concept is that the player organizes small trips to different destinations, in different periods of time and for different reasons and durations. Within the game, the player has to select the correct objects to put in his/her suitcase for specific destinations and trips (Figure 8). It stimulates observation, memory, critical thinking and concentration.

g) "Bird watching" is a digital game for tablet. In this game players pretend to be birdwatchers, they have to find and tap specific birds based on a photograph, find similar objects or hidden objects or irrelevant objects while traveling around a path (Figure 9). The game aims to stimulate memory, attention, observation and concentration and it includes different levels of difficulty.

h) "Flea market" is a digital game for tablet. The player has a shopping list and specific amount of money in his/her wallet. She/he visits the flea market of the neighbourhood and start shopping (Figure 10). Money management, memory and critical thinking are the main skills enhanced by the game.

6) Testing the eight prototypes of serious games

Game Session Workshops were organized in each country in order to evaluate the effectiveness of the games and their desired impact on PwD. Participants shared a positive feedback for the workshops and some comments for the improvements of the games. People appeared to enjoy the games, they didn't find any difficulty and no changes to the workshop it was introduced to make it easier. They underlined that it is very important for them to take part in similar workshops because they feel isolated and with more cognitive dysfunctions after the period of Covid-19 pandemic. Both health professionals and caregivers noticed that $\mathrm{PwD}$, clearly preferred physical games (in particular Specialites and 
Blooming flowers games). It seemed that $\mathrm{PwD}$ preferred physical games not only for the theme of the game but, mostly, due to the interaction aspects that seemed to lack while playing digital games. What made them having fun was not the
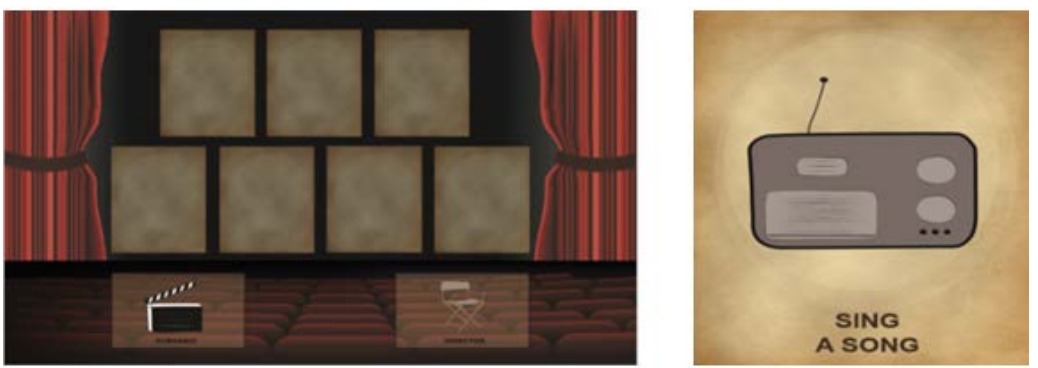

Figure 6. The physical game "The Directors".
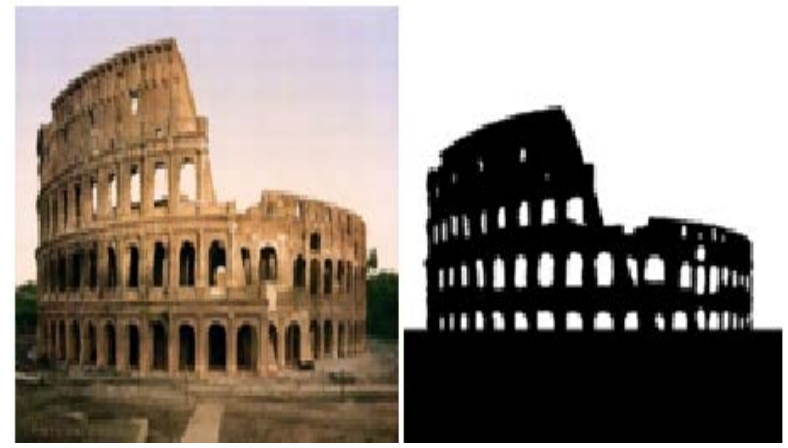

Figure 7. The digital game "Find it".

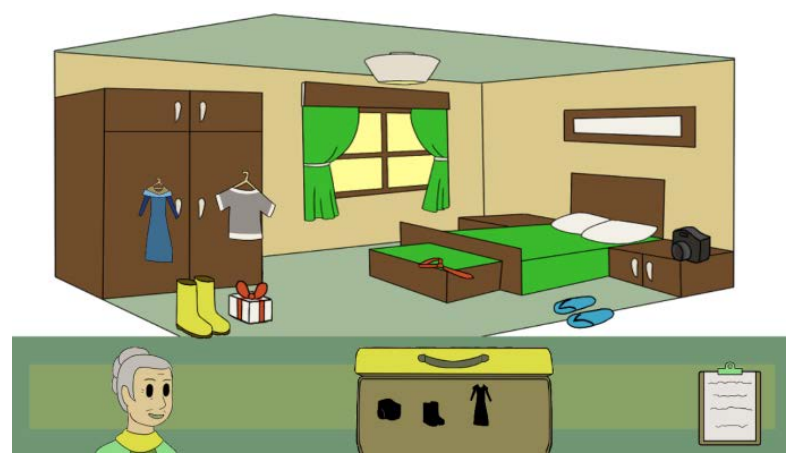

Figure 8. The digital game "Next destination".

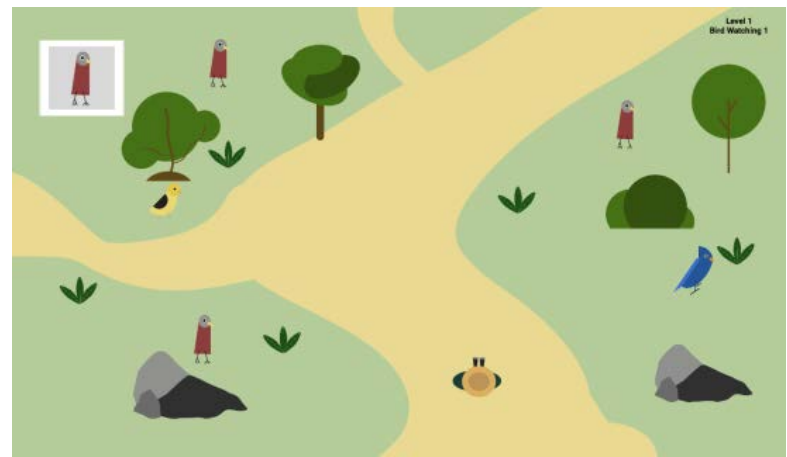

Figure 9. The digital game "Bird watching". 

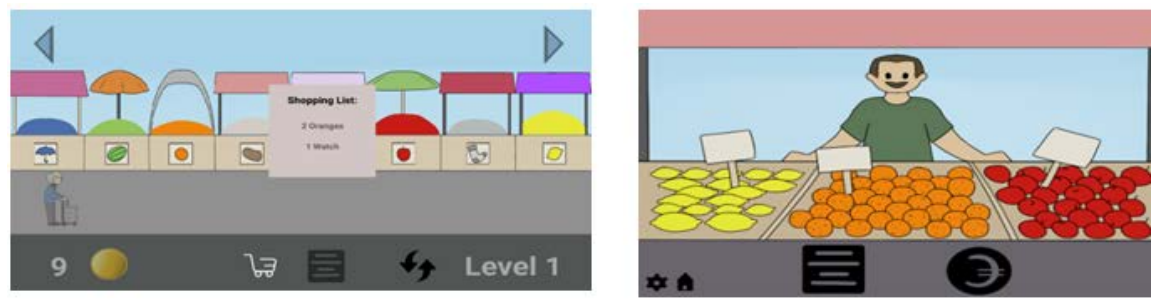

Figure 10. The digital game "Flea market".

game itself but the moment of sharing, doing something together. Health professionals noticed that $\mathrm{PwD}$ seemed to learn while playing games. At the beginning they found difficulties in playing digital games (they didn't know where tapping, they often asked for confirmations) while during the game session they acquired more and more confidence. Most participants didn't encounter many difficulties concerning the size of cards, images and letters, the graphic and the rules of the games. They proposed changes and improvements, though, such as increasing the size of some images in the digital games because they had visualized vision problems and some images were not clearly distinguishable while using a tablet. Some other proposed changes referred to the materials of the board games. For instance, like in the game "Blooming flowers" the cards with flowers slip on the large card and they move in the Flower shop card when they transfer the shop to another player and thus they proposed to change the boards of the game so as that the flower cards do not move, e.g to add a magnet under cards with flowers and also in the main surface of the Flower shop card. Also, some participants suggested to make the first level of the digital games a little bit faster because they found it boring.

\section{7) Finalization of games.}

The working versions of all the games, incorporating all the feedback from the Game Session Workshops are available online for further research. Anyone interested in using the boardgames can have access to printable files for boards and cards by download the material from the https://projectbridge.eu/. The phygital and digital games can be found also in Google play: https://play.google.com/store/apps/developer?id=Challedu https:/play.google.com/store/apps/details?id=com.companyname.findtheword https://play.google.com/store/apps/developer?id=ECE+Dev https://play.google.com/store/apps/developer?id=ECE+Dev https://play.google.com/store/apps/details?id=com.companyname.flea_market.

All the games have been uploaded to the e-platform for further research and application http://bridgecourses.uowm.gr/.

\subsection{Other Results of the Project}

The cocreation intergenerational workshops and the creation and testing of the games were among the main results of the games. As per application form the project had also two more deliverables: the methodological guide and the BRIDGE platform. 
The methodological guide highlights all the requirements on how to implement intergenerational workshops and events, the needs and specifications of games focusing on training on people with dementia and best practices on such interventions will allow the multiplication of the results of the project. All the project outputs were based on this methodological guide. Health practitioners along with product/game designers identified the key points of such interventions. In addition, they gave practical advice on the content of the various workshops held, identifying the needed resources. Moreover, brief guidelines on the content of the delivered prototypes of games were provided

Project partners have also created an online training platform (http://bridgecourses.uowm.gr/) including courses on general information of the project and dementia (needs and interactions with people with dementia), guidelines on how to conduct co-creating workshops and on the positive impact effects of serious games for $\mathrm{PwD}$, etc. A specialized module of this course is dedicated to the games designed, presenting thoroughly their concept, rules and possible impact on $\mathrm{PwD}$

\section{Discussion}

The data collected from game design workshops demonstrated that the structure of the Workshops and the way that they promote involvement of $\mathrm{PwD}$ and interaction with other people of different groups enhanced the level of satisfaction and contributed to their emotional well-being. These results are in accordance with a huge amount of research in the field of intergenerational interventions (Giraudeau \& Bailly, 2019; Andreoletti \& Howard, 2018; Teater, 2016; Galbraith \& Larkin, 2015; Biggs \& Knox, 2014; Kuehne, 2003).

Although there are past studies which have revealed that cognitive impairment and dementia are not prohibitive of participation or engagement in intergenerational programs, and that intergenerational programs may be equally beneficial for older people with and without dementia (Jarrott \& Bruno, 2003), there are also many studies which demonstrate that intergenerational programs could be especially beneficial for residents with cognitive impairment (Baker et al., 2017; Canedo-García et al., 2017; Low et al., 2015).

In addition, workshops combining intergenerational approach with playing games create awareness and motivation about the importance and possibilities of games as a tool for improving the quality of life of PwD. Participants also stated that they discovered the existence of SGs as innovative tools acting on cognitive and behavioral symptoms of dementia. The games of the workshops had benefits like stimulating memory abilities, attention, self-monitor and to perform goal-directed behavior. There are many researches in line with this result, that prove the effectiveness SGs to stimulate cognitive abilities of $\mathrm{PwD}$ (Chi et al., 2017; Zygouris et al., 2017; Hicks et al., 2016; Murayama et al., 2015; Robert et al., 2014).

The intergenerational programs can enhance cooperation and collaboration and involvement in activities that were related to real life. In other words, in our 
interventions, teamwork was an opportunity to focus on social interaction of older adults and PwD (LópezSeguí et al., 2019). According to Teater (2016), intergenerational interventions are reported as one type of social activity that may promote active aging among old people. This survey also underlines the enhancement of older people's confidence, self-esteem, and social skills, enables them to learn about others and feel connected to their community. Programs that bring together different generations can serve as key health promoters among older people by decreasing loneliness due to the greater sense of meaningfulness (Murayama et al., 2015).

According to our results, the involvement of professionals, young volunteers and $\mathrm{PwD}$ in the creation process of suitable games works as an intervention which bridges the generation gap and empower bonds between different groups (Gatti et al., 2017; Gamliel \& Nadav, 2014). It also gives the chance to young people to engage in volunteering actions concerning old people (Cohen-Mansfield \& Jensen, 2017).

It is proven by the results of "Bridge" project that the interaction of PwD with young people can enhance compassion of young people to older people and reduce the social stigma of the disease. This was a result by increasing the awareness of young adults about dementia. The intergenerational program, by Andreoletti and Howard (2018) which was designed as a brief service-learning experience to reduce age-related stereotypes, increased also the creativity of older adults. It is also crucial to underline the research by Miron et al. (2019), in which they examined the consequences of fear of incompetence in intergenerational relationships with PwD. People feel that they lack the knowledge and skills necessary for successful communication with $\mathrm{PwD}$, which leads to fear of incompetence.

Finally, involving PwD as co-designers in the development of SGs with the support of young people is deemed challenging, but not impossible. However, even with the update and expansion in the current project, specific insights in appropriate research methods and materials is still lacking (Andreoletti \& Howard, 2018). Extensive reports on the methodology and evaluation of the experiences of involvement of $\mathrm{PwD}$ themselves in combination with young people in interventions are generally missing. This makes appreciation of the active involvement of $\mathrm{PwD}$ and creates co-design difficulties within this combined field.

\section{Clinical Implications}

The intergenerational workshops, in which $\mathrm{PwD}$ and young people create and use SGs and the final result of this program can:

- improve cognitive and behavioral dysfunctions of PwD,

- narrow the gap between generations,

- decrease the stigma of dementia and promote civic participation of young people by developing the role of volunteering for social inclusion,

- create awareness and motivation about importance and possibilities of SGs as a tool for improving the quality of life of older people and their families. 


\section{Future Perspective}

Apart from this research and the Bridge project which finalizes on August 2021, future research and projects should therefore continue to concentrate on and characterize how methodologies and materials could be collected, designed and implemented. It has been proven that intergenerational programs which have a clear purpose and structure may be more successful in cultivating positive attitudes toward elders in the younger generation (Cook \& Bailey, 2013; Femia et al., 2008). The Bridge project has assessed the eight new games in a period of three months in which workshops with a specific structure and frequency took place. It is crucial to focus on results from longer implementation period (Leone et al., 2012).

In addition, through the results of this program, Alzheimer Associations can support and reinforce inclusive care for older people and $\mathrm{PwD}$ by using innovative methods and SGs. They can enrich their own practices and improve non pharmaceutical interventions for symptoms related to dementia. These workshops give the opportunity to improve the non-pharmaceutical interventions and assist the students and volunteers to respond to the need of their future work with older people and PwD. The intergenerational education can offer benefits to youngest to acquire all kinds of knowledge and skills that contribute to their immediate future, and improve the welfare of families and the community (Sánchez et al., 2015).

Finally, this project will enhance technology literacy of PwD through their participation in the workshops playing digital games. This activity can serve to create mutual learning through the use of mobile devices and generate security and motivation to PwD, thus reducing the digital divide (López Seguí et al., 2019).

\section{Acknowledgements}

The authors would like to thank the project team, Greek Association of Alzheimer's Disease and Related Disorders of Chalkida, Asociatia Habilitas-Centru de Resursesi Formare Profesionala (Romania), Anziani e non soloSocietà Cooperativa Sociale (Italy), Challedu (Greece) and University of Western Macedonia (Greece).

\section{Funding}

This work was supported and co-funded by Erasmus+ Programme of the European Union under Grant Agreement No. 2018-1-EL01-KA204-047892.

\section{Conflicts of Interest}

The author(s) declared no potential conflicts of interest with respect to the research, authorship, and/or publication of this article.

\section{References}

ADI Alzheimer's Disease International (2020). World Alzheimer Report 2019: Attitudes to Dementia. https://www.alz.co.uk/research/world-report-2019 
Alzheimer's Disease International (2020). Dementia Statistics. http://www.alz.co.uk/research/statistics

Andreoletti, C., \& Howard, J. L. (2018). Bridging the Generation Gap: Intergenerational Service-Learning Benefits Young and Old. Journal of Gerontology \& Geriatrics Education, 39, 46-60. https://doi.org/10.1080/02701960.2016.1152266

Baker, J. R., Webster, L., Lynn, N., Rogers, J., \& Belcher, J. (2017). Intergenerational Programs May Be Especially Engaging for Aged Care Residents with Cognitive Impairment: Findings from the Avondale Intergenerational Design Challenge. American Journal of Alzheimer's Disease and Other Dementia, 32, 213-221. https://doi.org/10.1177/1533317517703477

Berg-Weger, M., \& Stewart, D. (2017). Non-Pharmacologic Interventions for Persons with Dementia. Missouri Medicine, 114, 116-119.

Biggs, M. G., \& Knox, K. S. (2014). Lessons Learned from an Intergenerational Volunteer Program: A Case Study of a Shared-Site Model. Journal of Intergenerational Relationships, 12, 54-68. https://doi.org/10.1080/15350770.2014.869981

Canedo-García, A., García-Sánchez, J. N., \& Pacheco-Sanz, D. I. (2017). A Systematic Review of the Effectiveness of Intergenerational Programs. Frontiers in Psychology, 27, 1882. https://doi.org/10.3389/fpsyg.2017.01882

Chalfont, G., Milligan, C., \& Simpson, G. (2020). A Mixed Methods Systematic Review of Multimodal Non-Pharmacological Interventions to Improve Cognition for People with Dementia. Dementia (London), 19, 1086-1130. https://doi.org/10.1177/1471301218795289

Chi, H., Agama, E., \& Prodanoff, Z. G. (2017). Developing Serious Games to Promote Cognitive Abilities for the Elderly. 2017 IEEE 5th International Conference on Serious Games and Applications for Health, Perth, 2-4 April 2017, 1-8.

Cohen-Mansfield, J., \& Jensen, B. (2017). Intergenerational Programs in Schools. Journal of Applied Gerontology, 36, 254-276. https://doi.org/10.1177/0733464815570663

Cook, G., \& Bailey, C. (2013). Older Care Home Residents' Views of Intergenerational Practice. Journal of Intergenerational Relationships, 11, 410-424. https://doi.org/10.1080/15350770.2013.837802

D’Cunha, N. M., Isbel, S., McKune, A. J., Kellett, J., \& Naumovski, N. (2020). Activities outside of the Care Setting for People with Dementia: A Systematic Review. BMJ Open, 10, e040753. https://doi.org/10.1136/bmjopen-2020-040753

Femia, E. E., Zarit, S. H., Blair, C., Jarrott, S. E., \& Bruno, K. (2008). Intergenerational Preschool Experiences and the Young Child: Potential Benefits to Development. Early Childhood Research Quarterly, 23, 272-287. https://doi.org/10.1016/j.ecresq.2007.05.001

Galbraith, B., Larkin, H., Moorhouse, A., \& Oomen, T. (2015). Intergenerational Programs for Persons with Dementia: A Scoping Review. Journal of Gerontological Social Work, 58, 357-378. https://doi.org/10.1080/01634372.2015.1008166

Gamliel, T., \& Nadav, G. (2014). Knowledge Exchange, Social Interactions, and Empowerment in an Intergenerational Technology Program at School. Educational Gerontology, 40, 597-617. https://doi.org/10.1080/03601277.2013.863097

Gatti, F. M., Brivio, E., \& Galimberti, C. (2017). The Future Is Ours Too? A Training Process to Enable the Learning Perception and Increase Self-Efficacy in the Use of Tablets in the Elderly. Educational Gerontology, 43, 209-224. https://doi.org/10.1080/03601277.2017.1279952

Giraudeau, C., \& Bailly, N. (2019). Intergenerational Programs: What Can School-Age 
Children and Older People Expect from Them? A Systematic Review. European Journal of Ageing, 16, 363-376. https://doi.org/10.1007/s10433-018-00497-4

Hicks, B., Innes, A., Nyman, S., \& Cash, M. (2016). A "How to" Guide: Setting Up and Running Gaming Technology Groups for People with Dementia. Bournemouth University: BUDI.

Jarrott, S. E., \&Bruno, K. (2003). Intergenerational Activities Involving Persons with Dementia: An Observational Assessment. American Journal of Alzheimer's Disease and other Dementias, 18, 31-37. https://doi.org/10.1177/153331750301800109

Kuehne, V. S. (2003). The State of Our Art: Intergenerational Program Research and Evaluation: Part Two. Journal of Intergenerational Relations, 1, 79-94. https://doi.org/10.1300/J194v01n02 07

Lautenschlager, N. T., Anstey, K. J., \& Kurz, A. F. (2014). Non-Pharmacological Strategies to Delay Cognitive Decline. Maturitas, 79, 170-173.

https://doi.org/10.1016/j.maturitas.2014.07.012

Leone, E., Deudon, A., Piano, J., Robert, P., \& Dechamps, A. (2012). Are Dementia Patients Engagement Using Tailored Stimuli the Same? The Apathy Dilemma in Nursing Home Residents. Current Gerontology and Geriatrics Research, 2012, Article ID: 942640. https://doi.org/10.1155/2012/942640

LópezSeguí, F., de San Pedro, M., Aumatell Verges, E., Simó Algado, S., \& Garcia Cuyàs, F. (2019). An Intergenerational Information and Communications Technology Learning Project to Improve Digital Skills: User Satisfaction Evaluation. JMIR Aging, 2, e13939. https://doi.org/10.2196/13939

Low, F. L., Russell, F. M., McDonald, T., \& Kauffman, A. K. M. (2015). Grand Friends, an Intergenerational Program for Nursing-Home Residents and Preschoolers: A Randomized Trial. Journal of Intergenerational Relationships, 13, 227-240. https://doi.org/10.1080/15350770.2015.1067130

Miron, A. M., Thompson, A. E., Bagley, A., Anderson, J., Melotik, E., \& Rowley, S. (2019). Fear of Incompetence in Intergenerational Relationships with a Family Member with Dementia. Journal of Intergenerational Relationships, 17, 449-467. https://doi.org/10.1080/15350770.2019.1575783

Murayama, Y., Ohba, H., Yasunaga, M., Nonaka, K., Takeuchi, R., Nishi, M., Sakuma, N., Uchida, H., Shinkai, S., \& Fujiwara, Y. (2015). The Effect of Intergenerational Programs on the Mental Health of Elderly Adults. Aging and Mental Health, 19, 306-314. https://doi.org/10.1080/13607863.2014.933309

Office for the Ageing (OFTA) and the Department of the Premier and Cabinet (DPC) (2016). Better Together: A Practical Guide to Effective Engagement with Older People. https://www.bettertogether.sa.gov.au

Robert, P. H., König, A., Amieva, H., Andrieu, S., Bremond, F., Bullock, R., Ceccaldi, M., Dubois, B., Gauthier, S., Kenigsberg, P., Nave, S., Orgogozo, J. M., Piano, J., Benoit, M., Touchon, J., Vellas, B., Yesavage, J., \& Manera, V. (2014). Recommendations for the Use of SG in People with Alzheimer's Disease, Related Disorders and Frailty. Frontiers in Aging Neuroscience, 6, 21-29. https://doi.org/10.3389/fnagi.2014.00054

Sánchez, M., Kaplan, M., \& Bradley, L. (2015). Using Technology to Connect Generations: Some Considerations of Form and Function. Comunicar Journal, 23, 95-104. https://doi.org/10.3916/C45-2015-10

Teater, B. (2016). Intergenerational Programs to Promote Active Aging: The Experiences and Perspectives of Older Adults. Journal Activities, Adaptation \& Aging, 40, 1-19. https://doi.org/10.1080/01924788.2016.1127041

Tsolaki, M., Kounti, F., Agogiatou, C., Poptsi, E., Bakoglidou, E., Zafeiropoulou, M. et al. 
(2011). Effectiveness of Non Pharmacological Approaches in Patients with Mild Cognitive Impairment. Neurodegenerative Disorders, 8 , 138-145.

https://doi.org/10.1159/000320575

Zygouris, S., Ntovas, K., Giakoumis, D., Votis, K., Doumpoulakis, S., Segkouli, S., Karagiannidis, C., Tzovaras, D., \& Tsolaki, M. (2017). A Preliminary Study on the Feasibility of Using a Virtual Reality Cognitive Training Application for Remote Detection of Mild Cognitive Impairment. Journal of Alzheimer's Disease, 56, 619-627.

https://doi.org/10.3233/JAD-160518 